\title{
A remarkable insight into the cancer journey of Barbara Moss
}

\author{
Barbara Moss* \\ *Author for correspondence: bmoss2754@gmail.com
}

\begin{abstract}
Barbara Moss speaks to Roshaine Wijayatunga, Senior Editor Oncology at the 2018 European Society for Medical Oncology World Congress on Gastrointestinal Cancer (ESMO GI; Barcelona). Barbara Moss is a Patient Ambassador for EuropaColon and Bowel Cancer UK. At the age of 52, in 2006, Barbara was diagnosed with stage IV colorectal cancer of the colon, spread to the liver and was told she had 3-5 months to live! Barbara is now an active campaigner and an active member of several organizations in the UK and Europe. Her main wish is for patients to be able to access the medicine that they need, to have choices clearly explained and to be treated personally.
\end{abstract}

Published online: 19 October 2018

Before we talk about your diagnosis, I wonder if you could please tell us a little bit about your life before being diagnosed with cancer.

I've always thought about myself as just a very ordinary person. I was teaching, and actually this was a time of my life when everything was just right. I had a wonderful job in two schools in Worcester, I was married, happily, with two sons - they were doing well, they were going out to university, starting their first job - so nothing could have been better really.

In the summer of 2006 , you described yourself as getting unusually tired \& you put this down to the fact that you were getting older. You also mentioned that when reading up on symptoms that you had on the Internet, 'cancer' had been coming up, but you thought that could not really be happening. On speaking to other cancer patients, have you found this to be quite a common reaction when people experience unusual symptoms \& would you encourage people to just get checked up as soon as possible, even if they are sure there cannot be anything wrong?

Right, there's a lot in that. Going back, 6 years before 2006, I did have all the symptoms of bowel cancer, and I went straightaway to my doctor to be checked up, but I was misdiagnosed and was told I had hemorrhoids. We celebrated and we felt really great, because I thought, "well this is normal and it didn't need to be treated," - I could live with that. So it was over those 6 years, toward the end, I started to feel really tired and I started to exercise, thinking, I'm getting older, let's do a bit, but I was just getting more and more tired, rather than fitter. I went back to my doctor three-times, and again was misdiagnosed three-times! Following up on your questions, yes, I think, of course, patients must act on their symptoms. They really should follow-up; because, colon cancer, colorectal cancer is curable, if it's caught early, without too much risk at all. You'd be in hospital and out in a few days, so, any concerns, any worries, definitely, people should go and get checked straightaway - and given the opportunity of screening, just take it.

In your book, Who's been peeping in my bed?, you talk about the feeling of helplessness in the lead up to getting a diagnosis \& that only after you were told that you would not be going back to work until "you see the back of this [cancer]," you truly realized the seriousness of your situation. You say it takes a while for things to sink in, \& how one day your life continues as normal $\&$ the next you are lying in a hospital bed \& your outlook has changed, $\&$ things have been turned upside down in an instant. Can you tell us a little bit about this time?

It was just a blow. A complete blow. Although, I've explained to you, I did fear I had cancer, I had been told all along that I hadn't, so it wasn't until I was so anemic with a red blood count of six, that I was sent to A\&E for a

Future $\because$ Medicine 
blood transfusion. I had to wait a full day, and I could hardly sit on the chair. That was a dreadful day. I said to Mark, "go to work," and he came back from work and I was still sitting on the chair. It was the middle of the night when I was really looked at in a corridor, behind a curtain and then I was told that I might not be going back to work, and it hits you. That's when it really hit me, because I was almost saying, I can have the CT scan - it was a Friday, then go back to work. I was waiting for the scan, and I thought I could go back to work and come back for the scan, but I was told that I might have to wait longer for my scan if I go home, so just from that point, it was a cut-off from having worked the day before - it was complete shock.

What was it like to have that conversation with your husband Mark, \& your two sons, after you had been told your cancer was terminal?

Well, it was later on that night, when I was put into a bed and Mark asked, "what's the prognosis?" and he said there's no chance, 3 months and so this developed into more and more of - you can just imagine! Mark nearly fell off his chair, and then what was really the worst for me was imagining him telling my two sons and how difficult that must have been for him, and I think, I can just re-live it now.

One thing, actually I got from reading your book was that you had such a grace to be so positive \& remember your blessings amidst even such a painful reality $\&$ you talk about how you wanted others to be happy \& not to mourn \& you thought about how lucky you were \& that there was really nothing left undone that you had to do. Where did you find the strength to see the positives in such a difficult time?

You're talking about my poem. It was when Mark went home, I was on my own and I started to just think - I don't know - I didn't look for positivity, it was just how I felt. I felt I was lucky, I felt I'd had a good life, and that there was nothing that could not be continued with the family without me. But, they were the ones I was concerned for, because when someone dies, they are left bereft and they have that hole, that vacuum in their lives, and so that's really, the way they thought. Then, when you think, 3 months - that's not long at all! If you think back - "what have I done in the last 3 months" - it's not long! I wanted to leave something, so I wrote a letter to each one of them personally and how I'd imagine them getting married, and their children, and getting their degrees, and just for them to know I'd be there in spirit - and then I was there in reality when it happened because I'm alive!

And following-on from that, obviously, you describe the tremendous support, love \& prayers, you received from your family, including your mum, Mark your husband, your two sons Jevan \& Aidan, your mother-in-law, your brothers \& sister \& their families. How important was this for you?

Incredibly important. The family came together and I just got so much strength from that and really what it brings home to you is, "how do people manage if they don't have that?", because that just helped me so much, you know the feeling of love, that warmth, the arms around you, the care. I just think for the people who haven't got it ...

So the liver surgeon from the Queen Elizabeth Hospital in Birmingham said that if the tumor could shrink, he was prepared to operate \& remove it. How did it feel to have that hope to cling to?

This made all the difference. Because from first, a feeling of nothing we can do, only palliative, to if there's a chance, if this happens we can do that, it gave me a target and something to work for. It was the gastroenterologist who attended the multidisciplinary team (MDT) meeting and we were just so lucky that that one in 4 weeks was the week when the surgeon from Birmingham would attend that meeting. He was the one who from that point gave us the strength to go on.

Before your treatment started, you spoke in your book about wanting to do normal things, \& no longer taking things for granted. You also talked about feeling odd at being the center of attention. Can you tell us a little bit about this time pre-chemotherapy?

I'm not a person who likes too much attention focused on herself, and although, when I have strong views I express them (I'm that sort of person), I don't like being fussed over on the other hand. I felt a bit fussed over, the family gave me attention and they'd come to visit me and they wouldn't know what to say. I found that I was trying to 
cheer them up, so it was very odd. You'd sit there, and everyone would be attending to you. The nurses would be attending to you, family would be there sitting beside me and I just felt I wasn't worth that.

You had the peripherally inserted central catheter line inserted before Christmas \& your first chemo was scheduled for the second January. What was this Christmas like for you \& what went through your mind before chemotherapy? Did you react maybe differently to how you had expected to?

It was quite a saga because it was planned that I'd have my first chemo after Christmas, so Christmas could be normal for the family, but the peripherally inserted central catheter (PICC) line would be put in, so that I would be ready to go straight into it, the second of January, as soon as the chemo centers were functioning again. So, I went in for my PICC and I had an allergic reaction to it, and a raging temperature, and I had to go to hospital again, always the middle of the night when it happens - Mark would have to get up and take me. The A\&E was always quite a way away in Cheltenham - it wasn't the local hospital - so we'd have to go there, and I was in there over Christmas. It was not quite as planned but they allowed me to go home for Christmas day. I had planned to cook that Christmas, a special Jamie Oliver recipe with the turkey and so on, and do you know, Mark, Jevan and Aidan our two sons, they cooked the whole meal for me, and they had the music and the decorations. There are other things I can say about that Christmas, because I tried to keep it normal (and this is before I went into hospital). Every year, we've always brought an extra piece of decoration, and I wanted to do this the same and when I was buying this beautiful tinsel that we found that year, I was thinking, "I won't be here next year to see this," and these sort of thoughts, when you look at clothes, you think, "is it worth spending the money," but yes, it was a lovely Christmas and Mark took me back at the end of the day.

One striking statement you made in your book was, "I felt such a nuisance to everyone as I was causing so much disruption; they were flooding me with their love \& I was giving them nothing back in return." Do you find this to be a common feeling among cancer patients?

Yes, from being independent, you are suddenly helpless. You have to be cared for, you have to be taken to hospital. I know some people have to do it on their own. So there's always the consideration/the understanding of how difficult it must be for them, but I didn't have that. I was really cared for by my family and so I did feel a nuisance that life was suddenly for all of them, not just myself, revolving around me. Mark would have to take time off work to take me to my appointments and I had at least three appointments every week because between every chemo, there was a blood transfusion and after your chemo, you had to go back to have the 5-FU bottle removed, which had to last 3 days. Then, there would be other problems, I'd have sickness and have to go in, so, so many visits to hospital and having to take time off work. And so I was an absolute nuisance!

I can actually tell you about another lady who I met in the hospice [1], her name was Deidre. She was a volunteer and came to help me initially and then she was diagnosed with cancer. When I sat beside her, she said, "I'm not going to have any treatment," and I said, "Why not? Come on Deidre, be positive, come on!" And she said, "my son took me around Tesco and I just saw the look on his face and what he was going through and I thought, I don't want him to have to suffer that," and these are the experiences that you learn. She has a right to do what she wants, to have or to refuse treatment as she wants, but you do learn these things which people don't realize.

\section{You talk about your time at St Richard's Hospice \& how valuable it was, for example - something that stood out for me - being able to talk about death, actually, with people going through the same journey as you. Can you tell us a little bit about the hospice \& your experiences there?}

The hospice was a fantastic place for all of us and as soon as you entered the building, you just felt love - it was tangible. It was a happy place - you wouldn't think that, people are dying in there every day! But it is a happy place, and it's a strange thing, because cancer gave me peace of mind. I'd never experienced such peace of mind before. We did talk about all sorts of things, and that's why it is such a useful medium, to be able to talk to other patients who are going through what you're going through, because we all understand one another, and so it was completely open. We talked about coffins - the coffin we'd have, and the funeral we'd have. I planned my funeral - the songs, the music, the prayers. I can tell you about a few people individually. Deborah who I met there, she wanted a cardboard coffin with poppies and then I saw her in it at her funeral. Donna who wanted to be drawn through the little village she lived in, in a little pony-drawn glass chariot and then we were there. She wanted balloons - each 
one of us had to lift a balloon into the sky for her. Then, Liz who right at the end of her life, desperately wanted my book and to read my book [2], and so I specially went into the hospice to take it to her and I thought, "gosh, actually you're not going to be able to read this, but you wanted it," so I did that for her, and these are the things that we talked about.

There was a time after the chemotherapy had started that you heard that the tumor had grown, \& then your chemotherapy regimen had to be changed, \& you had to come to terms with the fact again that you were going to lose your hair, at that point as well. In the same period, you had to go into A\&E after your stomach started swelling. So can you tell us a little bit about this time?

Yes, it was over a period of a few months, and this was back in 2006 we're talking about, I know things have changed now. There were two main types of chemotherapy. I was given the first - the usual one, oxaliplatin $+5-\mathrm{Fu}$ and I really felt I was getting better. But after the four treatments, I was shocked to find out it had gone worse. I now had a $15-\mathrm{cm}$ tumor in my left liver and I was shocked to be told I had to have the other chemotherapy, because actually, those were the only two things at the time available on the NHS. That was standard practice.

There were a lot of concerns. I believed, I was thinking very, very positively and I believed the tumor had shrunk, so when I was told the chemotherapy hadn't worked, I was shocked. And they would have to change it. I was now put on irinotecan - the only other option available on the NHS. Yes, I had to go and get my wig and so on to be prepared. Then, my surgeon had said that if that tumor had shrunk, he was prepared to operate and it would be the entire left liver lobe, which now had this $15-\mathrm{cm}$ tumor, and also the entire ascending colon. When my stomach started to swell, there was a blockage that the tumor in my colon was blocking, and I was worried, because I knew if this happened, it was an emergency. I was in hospital and they might have to operate. It's quite a funny incident and very personal because I was put into the ward and by, I think it was the next day, my bowels opened and I was in a shared room of four ladies and I just sang "Alleluia" at the top of my voice and I think everyone knew exactly what had happened.

So then you got some positive news, because you had been told that the tumor had shrunk by $\mathbf{2 5 \%}$ in both directions. Why was this still not enough for the operation to take place?

The tumor was one large solid tumor in my liver in the left liver lobe and it was much too close to the portal vein. There had to be a clearance of 2 clear millimeters for them to be able to operate. The rest of the lobe they had planned to take away. So, that was the critical factor - that it wasn't sufficiently away from the portal vein, so I had to wait longer.

You have been through such a mixed bag of emotions. In one section of your book you say, "Mark \& I left feeling terribly, terribly disappointed; this was such a journey," \& then you go on to say, "However, I had got this far \& there was no giving up or turning back now." Sometimes being on the outside, we may not fully appreciate the extent of the emotional highs \& lows during cancer treatment. Can you tell us, did you do anything specific to manage your emotions \& cancer mentally?

I think we always just looked at things one step at a time and that was very, very important. Not to think well, "when that happens, or this, or that," but it was just one step at a time, all the way along. The strange thing about my cancer journey was that I did have total peace of mind and I've never really experienced that before or after. I tried to gain it back, but I had total peace of mind and I felt that life could go on with the family without me. It wouldn't be the same, but they were all in a position where they could cope, and so that helped me a lot. Though I accepted the disease, it wasn't anybody's fault, I was told it wasn't my fault - but it didn't mean giving up. We just took it as it came.

Can you tell us a bit about the moment you were recommended Avastin - at that time, that was not freely available on the NHS, \& had to be paid for privately, \& then how the treatment worked \& the outcome for you?

When the effects of the chemotherapy was diminishing, I felt that I was on a losing slope because I was getting more and more tired, the side effects were building up and I'd felt that maybe I wouldn't be able to continue and there was nothing else. We then read about things that were being done in Europe and in America and asked about 
them and I was told, "yes, but they weren't available on the NHS." We tried to appeal and so on, ask the primary care trust (PCT) ... and they still refused me, so we decided to pay for it. My surgeon as well as my oncologist were very, very helpful and my surgeon said that if that tumor would shrink away from the portal vein, which is where the clearance had to be, that he would operate, so we had a target. Maybe having this new medicine would be helpful. We were quite keen on being able to access it and we decided in the end to pay for it ourselves.

Tell us about your feelings when you finally got that phone call from your surgeon that he was happy to operate, \& then why did you have to wait 6 weeks after your last chemo treatment for the operation to take place?

Well, Mark and I used to try and take little breaks in between chemo and we were actually in - I am trying to remember the name of the place but I just can't remember it - but we weren't that far from home - we were always within 1-hour journey back from home. But we were on a campsite. We got that phone call and he said yes, he said, now is the time, we have taken the $\mathrm{x}$-ray ... and we just celebrated! Mark played music - he plays the guitar - and was singing, and people could hear us across the field. It was really, really a lovely time. It was important to wait the 6 weeks because all your system has to go back to normal and your strength has to build up again from the chemo - the effects of the chemo have to lessen.

\section{Are you able to tell us a little bit about the surgery? Did you fully understand what was going to happen during the procedure $\&$ the full extent of the risks associated with it?}

Yes. I was told very, very clearly - the risk was high that I wouldn't come out of it. But yet, I was so happy to have the chance because I really didn't want to carry on forever, and I was thinking that I don't want to be a burden on the family. I accepted what was happening to me, but I wanted to go for it - for the operation, but I was told very clearly that I might not come out. It would involve two complete teams of surgeons - the gastroenterologist and then liver surgeon - so it was like two separate operations, one after the other, but even though I knew that this might be the last few minutes of my life as I went in, I accepted that and I thought - "lucky to have that chance."

Despite the seriousness of the operation, you describe the feeling of excitement going in ... It's a strange thing, because my wonderful surgeon, he said I'm the only person who has had a smile on my face all the way through the operation. Yes, I was really happy to have that chance. I felt lucky.

What happened in the period soon after the operation? You describe severe pains in your stomach \& then you also tell the story about the MRSA worry in the ward, \& then you talk about how different patients in the ward reacted to their conditions, \& even noisy shelves being put up in the room near you. So you had a lot to deal with during at the same time. I imagine my senses were heightened by the morphine. I had this morphine pump that I could operate myself - but they wouldn't let you overdose on it. So, I imagine some of it was because I was on morphine, and in that intensive care ward, once I'd come out of that operation, I was fighting for my life. In my mind, there was that - when you don't want to give up, you don't want to lose. I didn't want anything to get in my way. I could see the nurses in the opposite bed cleaning the wall and I overheard their conversation, because I think with the morphine it enhances your senses, and they were talking about what they were doing and that they had a patient there with MRSA and I thought, "I’m not staying here!" - I was absolutely wanting to survive, so in fact, they moved me out of the ward, out of the intensive care, because I wasn't happy to be there, and so that really is the story.

\section{You describe the period where you had to have your stomach drained, \& how terrible that was for you. What events led to that happening?}

Well, I had a blockage, and my bowels weren't functioning and so my stomach inflated, and I really felt I was going to burst! And it was rock hard and huge! I had stitches - 50 staples - across the cut, across my chest - it went all the way from the right-hand side to the left-hand side entirely and I thought if this expands anymore - because it was hard - I am going to burst. I was more concerned about the clips popping out than even the pain, or anything else. I really wanted that operation to be a success, and so I was really, really worried. 
In your book, you describe the catalog of events that led up to the results of a report stating that the lymph now showed adenocarcinoma, which is the same cancer as your primary, so the cancer had then spread. How did you feel after hearing this news \& what happened next? It was Christmas time again and I remember there was a special Doctor Who program on. Our two sons were there watching with Mark and I didn't want to disturb them, but I could feel this lump just as though expanding in my throat. After the program, I spoke about this and I wanted it to be checked and I phoned up. I was told, "don't worry about it," but I insisted on a check-up and it was out of hours. I just went into the hospital on my own the next morning - I didn't have an appointment because Mark and I had planned a 4-week trip around France, and this was just 3 days before now! At the hospital, they did test it and it was found that the cancer had returned in my lymph and my oncologist did say to go away for 2 weeks if you like and then they would start treating afterward, but I don't know really how I can describe it, but I was fighting for survival and I felt that emotion - that I didn't want anything to come between and I didn't want the risk of delaying, and so I wanted the treatment straightaway.

\section{After all of that happened, then eventually, you were given the news that your CEA level had reduced to $1.6 \&$ the swelling in the lymph gland had totally regressed. That must have felt amazing! So what were the next steps then after that?}

Well, I had been asked several times at St Richards Hospice, and they were such wonderful people, I had talked to them and they said, "what about writing about your story? Write it down!" because they knew had been an English teacher and I thought, "I have not done this yet!" - there was this feeling of guilt. I thought, "I must write about this now." I wanted to give back something to the people who'd helped me - Bowel Cancer UK [3] - who had been fantastic in helping me through my appeals, in trying to get the medicines that I needed, the hospice who'd always cared for me - it is such a wonderful place, meeting other people - it's not a sad place at all - it's a very calm, peaceful, wonderful place, where you have complete peace of mind. So, I wanted to give back really, and so that was the next step - I wanted to write.

So, we'd love to hear the story then of the drug \& your PCT - you spoke about Bowel Cancer UK - how they were very helpful during this time, especially following the initial refusal of funding, $\&$ there was much publicity $\&$ an appeal hearing. Can you tell us a little bit more about this?

Yes, because I needed a private drug to be added to my usual regimen, I asked for it and I was refused. Then, Bowel Cancer UK helped me to appeal for it, and we actually took it to the panel. I attended the hearing, I spoke personally. They refused me the medicine and we had to pay for it, so these are all worries - cancer doesn't wait for decisions like that. You have to act. My mum paid for half the treatment. At that time, you lost all your treatments if you wanted one private drug added, so it was a big decision and it was going to cost several thousands of pounds, and I thought I wasn't worth it - leave money for the family, for the people who are living, but they all wanted me to have it. It was a big decision and we decided to pay, but my thoughts are, what about other patients, what about those people who can't find the money - we had to find the money - but what about the people who can't? We have to have a fair system.

\section{So, how did you feel then knowing that you had a part to play in the governments promise to review \& then release new guidelines for PCTs?}

My concern was for fairness, as I think I have already expressed, and equal treatment. It wasn't just the money side of it, it was the fight for it and the fairness for it and expressing your views, and I actually attended the hearing when they decided - they didn't tell me on the spot that I wouldn't have funding for this drug, they told me later on, but I was able to stand there and express my viewpoint - (nonetheless, I felt it had not been listened to) but at least I had done it. There is something in that, because you can go away with your thoughts, and you can talk about them later on and you can express your views politically and openly to the system, because you've gone through it and experienced it and you can try to make it fairer. 


\section{You are involved with a lot of different societies, one of which is Bowel Cancer UK, \& the other one - EuropaColon, \& you are a patient ambassador for those two. Can you tell us a little bit about your involvement there?}

Certainly, all patients like myself who can relate to their experiences in order to help others, and to make a fairer system - that is what Bowel Cancer UK and EuropaColon do - they try to gain access to drugs to make a fairer system to help patients in that situation, to look at the legal system, to try to make it right, and with EuropaColon, it is across Europe [4]. It just varies so tremendously from one country to another - the access to drugs, the treatment of patients, so it helped me to express my feelings to become involved, and it also helped me to give back something - it was a medium through which, I could give back all the help that had been given to me, and they had helped me. So, to me, it's not just access to drugs, it's raising awareness, it's helping people to live healthier lives, it's helping people to ask for what they want and to express their own views and not just be told what to accept - you do have a choice and to help save lives in the end - that's what you're doing.

\section{You ended your book by saying you will all be more prepared "when the cancer does return." Now, the book was published in 2009, I believe, \& we are almost 10 years later! How have you been Barbara?}

There have been ups and downs. The NHS have been wonderful. Once you're in the system - I've been looked after very, very well. I've had regular checkups, and when I've had concerns, they've answered my questions, my doctors have all been fantastic. The ups and downs have been with my tumor markers, which have been worrying at times, and in fact, I did have the one recurrence that we talked about already, so there are stressful times. At the beginning, it was always stressful, waiting for results to see whether your tumor marker was still within normal range or not, but from the beginning, I was told that my chances were - the cancer would return and I always asked the question - "How long?" and it was "Within 3 years." That was quite a threshold for me to get over those 3 years, and then I started not to worry so much, because I actually thought, "Well, I've actually had 3 years, I'm now very lucky!" Even if something happens, you can't stop worrying of course, but I've been lucky, so you look at the positive side. Two years ago, maybe 3 years ago now, my tumor markers did rise consecutively into abnormal - and I was very worried and being a patient within patient groups, such as EuropaColon and Bowel Cancer UK, I knew what to do, and this is what we try to advise other patients - that is - to really insist on having all those checks. I had all the checks possible and they all came out clear. And now for the first time in 2 years, my tumor marker - called a CEA for bowel cancer/colon cancer has gone back to normal. It's great! And these are the things that perhaps other people don't realize - there are stressful times.

\section{What projects are you currently working on \& what is next for you?}

Really, I felt that I had so much help given to me that I wanted to give something back and I have to do it, and I feel I have to do that. I'm heavily involved in advocacy. I'm a patient ambassador for EuropaColon, and also for Bowel Cancer UK. I have done work for EMA and for NICE as well during licensing of drugs and discussions on that, I'm a patient advocate for Inspire2Live, which is a Dutch organization, I've done a lot of work for the European Organisation for Research and Treatment of Cancer (EORTC) on some of their projects, I also work for the company called S:CORT and a subgroup of that is a public patient involvement engagement consortium, which we are involved in. I've also done work with the SGC which is a genomic consortium in Oxford, and European Access to Patient Medicines and personally asked to comment and speak for various organizations including pharmaceutical companies from time to time. Really, I'm very happy to be involved in such a way, in order to help other patients gain access to the drugs that they need and the right treatment.

\section{Do you have any closing remarks you'd like to make to our readers/listeners?}

I think every patient is an individual. I think everyone has personal needs and everyone should be considered as a person and so when you go to your doctor, there is not just one treatment to fit everybody and that is being discovered more, and more and more today. Colorectal cancer is just not one disease. You don't just have that. There are so many different types of it and so many different treatments and then your body is working against it as well, against that treatment, trying to stop it working - it's so odd to imagine. The main thing is for patients to be able to express their own needs, and to be looked after as an individual and for the doctor to look at them and see what that patient needs. Some patients want treatment, some patients don't want treatment and every wish should be inspected. I remember Kate Granger who started her campaign \#Hellomynameis - and I always refer to her - 
"Doctor, please look at me, I'm a person." These are what patient groups also try to address in the system, so that the patients can get the treatment and in the end we will save money through doing that because the diagnosis, awareness, healthy eating, exercise, I'm sure I'm missing out a ton of things, but every single factor is important. We should be responsible as people, to lead healthy lives, but every case of cancer can't be put down to - the person hasn't done that, whatever. If the person falls into that category where they are unfortunate and they are ill, we must take care of them! We have responsibilities to do that and the patient organizations help the patients to do that.

\section{Financial \& competing interests disclosure}

The author has no relevant affiliations or financial involvement with any organization or entity with a financial interest in or financial conflict with the subject matter or materials discussed in the manuscript. This includes employment, consultancies, stock ownership or options, expert testimony, grants or patents received or pending, or royalties.

No writing assistance was utilized in the production of this manuscript.

\section{Disclaimer}

The opinions expressed in this interview are those of the interviewee and do not necessarily reflect the views of Future Medicine Ltd.

\section{Open access}

This work is licensed under the Attribution-NonCommercial-NoDerivatives 4.0 Unported License. To view a copy of this license, visit http://creativecommons.org/licenses/by-nc-nd/4.0/

\section{References}

1. St Richard's Hospice. www.strichards.org.uk/

2. Moss B. Who's Been Peeping in My Bed? Aspect Design, Malvern, UK (2009).

3. Bowel Cancer UK. www.bowelcanceruk.org.uk/

4. EuropaColon. www.europacolon.com/ 